\title{
A Randomized Controlled Trial Comparing the Efficacy of P6 Acupuncture Plus Ondansetron versus Ondansetron or P6 Acupuncture in the Prevention of Nausea and Vomiting after Bupivacaine-Morphine Spinal Anesthesia
}

\author{
Chang Yen Yin 1*, José Reinaldo Cerqueira Braz², Wei Tzon Hackan Chang Colares ${ }^{3}$, \\ Lídia Raquel de Carvalho4, Marília Pinheiro Módolo², Paulo do Nascimento Junior², \\ Norma Sueli Pinheiro Módolo²

\begin{abstract}
${ }^{1}$ School of Physical Education and Physiotherapy, Federal University of Amazonas, UFAM, Manaus, Brazil
${ }^{2}$ Department of Anesthesiology, School of Medicine, Botucatu, University of São Paulo State, UNESP, Botucatu, Brazil

${ }^{3}$ School of Medicine, Federal University of Amazonas, UFAM, Manaus, Brazil

${ }^{4}$ Bioscience Institute, Botucatu, University of São Paulo State, UNESP, Botucatu, Brazil
\end{abstract} \\ Email: *changyenyin@hotmail.com
}

How to cite this paper: Yin, C.Y., Braz, J.R.C., Colares, W.T.H.C., de Carvalho, L.R., Módolo, M.P., do Nascimento Junior, P. and Módolo, N.S.P. (2017) A Randomized Controlled Trial Comparing the Efficacy of P6 Acupuncture Plus Ondansetron versus Ondansetron or P6 Acupuncture in the Prevention of Nausea and Vomiting after Bupivacaine-Morphine Spinal Anesthesia. Open Journal of Anesthesiology, 7, 253-263. https://doi.org/10.4236/ojanes.2017.78026

Received: July 18, 2017

Accepted: August 22, 2017

Published: August 25, 2017

Copyright (c) 2017 by authors and Scientific Research Publishing Inc. This work is licensed under the Creative Commons Attribution International License (CC BY 4.0).

http://creativecommons.org/licenses/by/4.0/

cc) (7) Open Access

\begin{abstract}
Objective: To compare P6 acupuncture plus ondansetron with either ondansetron or P6 acupuncture in the prevention of postoperative nausea and vomiting (PONV) in patients submitted to spinal anesthesia. Methods: A randomized controlled trial was performed with 90 patients undergoing orthopedic surgery under spinal anesthesia with bupivacaine, 15 to $17.5 \mathrm{mg}$, and morphine, $100 \mu \mathrm{g}$. They were assigned to one of the three groups: Group Ondansetron $(n=30)$, patients were given ondansetron, $8 \mathrm{mg}$ intravenously, before spinal block was performed; Group P6 acupuncture $(\mathrm{n}=30)$, patients were subjected to bilateral electrical stimulation of P6 acupoint for 30 minutes before anesthesia; and Group P6 acupuncture plus ondansetron $(n=30)$, the exact combination of the groups Ondansetron and P6 acupuncture. Results: In the post anesthesia care unit, the incidence of nausea and vomiting ranged from $13.3 \%$ to $26.7 \%$ and from $6.7 \%$ to $13.3 \%$, respectively, with no significant differences among groups $(p>0.05)$. Ondansetron group had the highest incidence of nausea $(73.3 \%)(p<0.001)$ and vomiting $(43.3 \%)(p<0.001)$ at the ward from 0 to 24 hours, followed by P6 acupuncture (33.3\% and 26.7\%) and P6 acupuncture plus ondansetron groups (16.0\% and 0\%). Conclusion: Preoperative stimulation of P6 acupoint in combination with ondansetron has higher efficacy than either P6 acupoint stimulation or the administration of
\end{abstract}


ondansetron on the prevention of PONV in patients submitted to bupivacaine-morphine spinal anesthesia.

\section{Keywords}

Anesthesia, Nausea, Vomiting, Acupuncture, Ondansetron

\section{Introduction}

Postoperative nausea and vomiting (PONV) is one of the commonest complications after anesthesia. It has been reported that at least one in each four patients suffers from PONV [1] [2]. Then, the prevention and treatment of nausea and vomiting have become important subjects in anesthesiology [3]. Currently, even with new anesthetic techniques, which involve the use of prophylactic agents and the selection of anesthetics with lower emetic potentials, the incidence of PONV has not decreased and is still approximately $20 \%$ to $30 \%$ [4] [5] [6].

The efficacy of antiemetic drugs is limited and their administration is not free from side effects [7] [8]. No isolated intervention can completely prevent or treat PONV. Several factors may still be associated with a higher incidence of PONV, including patients under the age of 50 years, female sex, abdominal surgery, nitrous oxide administration and longer duration of anesthesia [9] [10].

Acupuncture has been used as a non-pharmacological technique for the prevention of nausea and vomiting in situations such as pregnancy [11] [12], post-chemotherapy [13] [14] and during the postoperative period [15] [16]. Nonetheless, due to the variable quality of the studies and heterogeneity, there has been inconsistency on the efficacy of acupuncture as a prophylactic or treatment therapeutic in all these clinical scenarios [17] [18] [19] [20].

Acupuncture can be used alone or combined with conventional antiemetic drugs. Evidence is inconclusive concerning the use of a combined strategy of P6 (Neiguan) acupoint stimulation with antiemetic drugs over pharmacological prophylaxis on the prevention of PONV [21]. The objective of this study was to evaluate the efficacy of the combination of P6 acupoint stimulation plus the administration of ondansetron compared with the administration of either ondansetron or P6 acupoint stimulation in the prevention of PONV in patients undergoing orthopedic surgeries under spinal anesthesia with bupivacaine plus morphine.

\section{Methods}

After the approval by the Research Ethics Committee of the Federal University of Amazonas, UFAM, CAAE 4679.0.000.115-09, this prospective randomized controlled trial was conducted from may 2010 to December 2011 in the Hospital Universitário Getúlio Vargas and in the Fundação Hospital Adriano Jorge, Manaus, Amazonas, Brazil. The study is in accordance with the CONSORT state- 
ment, the Brazilian Standards of Good Clinical Practice and the Declaration of Helsinki. All the participants provided written informed consent before undergoing any procedure.

Ninety patients undergoing elective orthopedic surgery of the lower limbs or hips, aged 18 years or older, of both sexes, physical status 1 or 2 according to the American Society of Anesthesiologists (ASA) and capable of reporting researched symptoms were included. The exclusion criteria were fear of acupuncture needles, impossibility of using the P6 and LI11 (Quchi) acupoints, patients using any antiemetic drug for 48 hours previously to the surgical procedure and the need of general anesthesia at any moment after the performance of spinal anesthesia.

The groups were differentiated by the opening of a sealed envelope one hour before the surgical procedure, as follows: Group Ondansetron $(n=30)$, patients were given ondansetron, $8 \mathrm{mg}$ intravenously (IV), 5 minutes before spinal block was performed; Group P6 acupuncture $(n=30)$, patients were subjected to bilateral electrical stimulation $(10 \mathrm{~Hz})$ of the P6 acupoint with LI11 as a neutral acupoint for 30 minutes before anesthesia, performed at the post anesthesia care unit; and Group P6 acupuncture plus ondansetron $(n=30)$, the exact combination of the groups Ondansetron and P6 acupuncture. P6 acupoint is located on the anterior surface of the forearm between the tendons of the flexor carpi radialis and the palmaris longus, next to the median nerve, two Chinese inches (one Chinese inch $=1.5$ to $2 \mathrm{~cm}$ ) proximal to the distal wrist crease. LI11 acupoint is located on the lateral end of the elbow crease, in a depression between the end of the crease and the lateral epicondyle of the humerus, on the extensor carpi radialis longus muscle.

At the operating room, patients were monitored with a 3-lead electrocardiogram, noninvasive blood pressure and pulse oximetry. An intravenous line was obtained in the upper limb with a $18 \mathrm{G}$ or $20 \mathrm{G}$ catheter and lactated Ringer's solution was administered at 8 to $10 \mathrm{ml} \cdot \mathrm{kg}^{-1} \cdot \mathrm{h}^{-1}$. Additional boluses of lactated Ringer's solution were administered according to clinical judgment. The patients were sedated with midazolam, 3 to $5 \mathrm{mg} \mathrm{IV}$, and fentanil, 30 to $50 \mu \mathrm{g} \mathrm{IV}$, and received supplemental oxygen through a nasal catheter at a rate of $21 \cdot \mathrm{min}^{-1}$. The administration of the spinal anesthesia followed a standard technique: with the patient seated, puncture with a 25 G Quincke needle via median access in the $\mathrm{L}_{3}$ - $\mathrm{L}_{4}$ or $\mathrm{L}_{4}-\mathrm{L}_{5}$ intervertebral spaces was performed. After the visualization of the cerebrospinal fluid, 15 to $17.5 \mathrm{mg}$ of hyperbaric or isobaric $0.5 \%$ bupivacaine plus morphine, $100 \mu \mathrm{g}$, were injected with independent syringes. The anesthetic was injected at a rate of $1 \mathrm{ml} \cdot 10 \mathrm{~s}^{-1}$. Immediately after the administration of the drugs, the patients were placed in the supine position and thermal sensitivity and motor blockade levels were evaluated. Values of systolic blood pressure lower than $90 \mathrm{mmHg}$ and values of heart rate lower than 45 beats. $\mathrm{min}^{-1}$ were treated with administration of ephedrine, $5 \mathrm{mg} I V$, and atropine, $0.5 \mathrm{mg}$ IV, respectively. Postoperative analgesia was provided with tramadol hydrochloride, 1 $\mathrm{mg} \cdot \mathrm{kg}^{-1} \mathrm{IV}$ (maximum dose: $100 \mathrm{mg}$ ) and with metamizole, $25 \mathrm{mg} \cdot \mathrm{kg}^{-1} \mathrm{IV}$ 
(maximum dose: $2 \mathrm{~g}$ ). After the surgery, the patients were kept at least 2 hours at the post anesthesia care unit and were transferred to the ward when a score nine or 10 was achieved on the modified Aldrete-Kroulik score.

When patients presented with nausea and/or vomiting, the rescue treatment was ondansetron, $4 \mathrm{mg} \mathrm{IV}$, in all groups.

The outcome evaluated was the incidence of nausea and/or vomiting in the post anesthesia care unit and in the surgical ward within the first 24 hours after surgery. Independent evaluators not aware of the groups being studied were invited to evaluate the patients and the outcome. PONV was considered when any episode of either nausea or vomiting, or both, occurred. The investigators recorded the presence of any other complains or observed side effects.

\section{Statistical Analysis}

The sample size was calculated based on a reduction of the incidence of postoperative nausea and vomiting in 50\% with the combination of antiemetic drug and acupuncture, considering the estimated incidence to be $75 \%$ [1]. With a test power of $80 \%$ and a significance set at $5 \%$, a minimum of 30 patients per group were necessary to detect differences between groups. After electronic randomization, three groups of 30 individuals were composed. Allocation concealment was provided by opaque envelopes numbered from one to 90 and the study followed the numeric order of the envelopes. For the categorical variables, the Fisher's exact test was performed and was followed by a post hoc pair wise comparison when any difference was detected. For the quantitative variables, ANOVA was performed and was followed by a Tukey's test when any difference was detected. The significance level used was $5 \%$.

\section{Results}

The flow diagram of patients included in the study is shown on Figure 1. The three groups studied were homogeneous in terms of characteristics of patients and possible risk factors for postoperative nausea and vomiting (Table 1).

The incidence of nausea was significant different among groups in the surgical ward, with a significant reduction for P6 acupuncture plus ondansetron group in comparison to Ondansetron group $(p<0.001)$, and for P6 acupuncture group in comparison to Ondansetron group $(p<0.004)$ (Table 2).

The incidence of vomiting was significant different among groups in the surgical ward, with a significant reduction for P6 acupuncture plus ondansetron group in comparison to both Ondansetron group $(p<0.001)$ and P6 acupuncture group $(p=0.004)$ (Table 2).

No side effects were observed in relation to acupuncture or the use of ondansetron at any time.

\section{Discussion}

The main finds of our study were that the combination of P6 acupuncture with 
ondansetron reduced the incidence of nausea at the postoperative period, in comparison with the use of ondansetron, and also reduced the incidence of vomiting at the postoperative period in comparison to both ondansetron and P6 acupuncture. P6 acupuncture alone was no better than ondansetron to reduce the incidence of postoperative vomiting.

P6 acupoint has been used as a strategy to prevent the occurrence of PONV. It was from the observations of the use of the manual pressure in P6 acupoint as prophylaxis against vomiting in early pregnancy at the People's Republic of China that the first clinical studies were started in anesthesiology [22]. The elec-

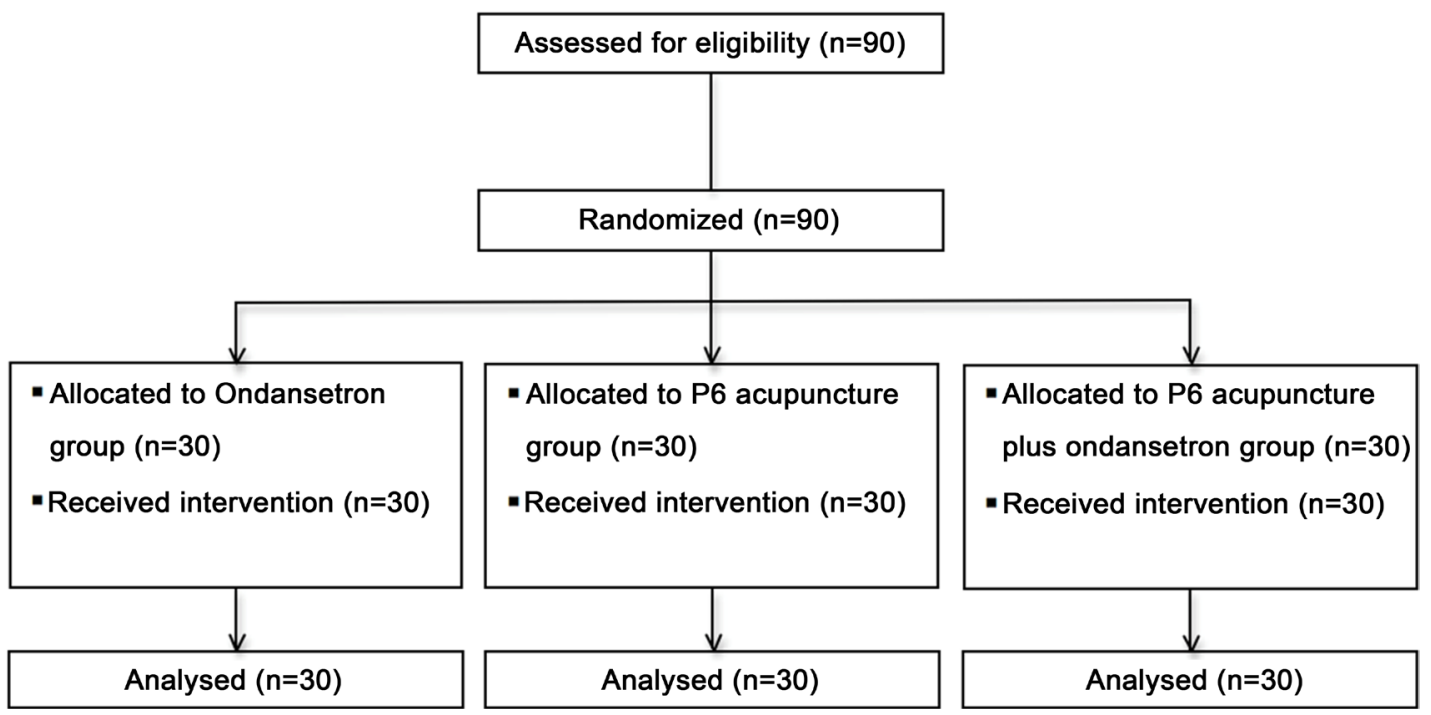

Figure 1. CONSORT flow diagram of patients included in the study.

Table 1. Characteristics of patients according to each group and length of surgery. Values are mean \pm standard deviation or number.

\begin{tabular}{ccccc}
\hline & \multicolumn{4}{c}{ Groups } \\
\cline { 2 - 4 } & $\begin{array}{c}\text { Ondansetron } \\
(\mathrm{n}=30)\end{array}$ & $\begin{array}{c}\text { P6 acupuncture } \\
(\mathrm{n}=30)\end{array}$ & $\begin{array}{c}\text { P6 acupuncture } \\
\text { plus ondansetron } \\
(\mathrm{n}=30)\end{array}$ & $p$ value \\
\hline Age; years & $39.7 \pm 14.8$ & $37.1 \pm 12.4$ & $34.8 \pm 11.2$ & 0.341 \\
Sex; male/female & $23 / 7$ & $23 / 7$ & $25 / 5$ & 0.765 \\
Weight; kg & $73.2 \pm 11.4$ & $73.4 \pm 13.4$ & $78.3 \pm 19.1$ & 0.334 \\
Height; cm & $167 \pm 8$ & $167 \pm 6$ & $169 \pm 9$ & 0.572 \\
Body mass index; kg.m ${ }^{-2}$ & $26.3 \pm 3.6$ & $26.1 \pm 4.2$ & $27.2 \pm 5.2$ & 0.583 \\
ASA physical status; $1 / 2$ & $27 / 3$ & $28 / 2$ & $27 / 3$ & 0.871 \\
Systemic hypertension; yes/no & $3 / 27$ & $2 / 28$ & $3 / 27$ & 0.871 \\
Diabetes Mellitus; yes/no & $1 / 29$ & $1 / 29$ & $0 / 30$ & 0.599 \\
Tobacco use; yes/no & $8 / 22$ & $6 / 24$ & $7 / 23$ & 0.829 \\
Motion sickness; yes/no & $3 / 27$ & $3 / 27$ & $1 / 29$ & 0.538 \\
Length of surgery; min & $102 \pm 48$ & $101 \pm 49$ & $96 \pm 58$ & 0.881 \\
\hline
\end{tabular}


Table 2. Number (percentage) of patients presenting nausea or vomiting in the post anesthesia care unit (PACU) and at the surgical ward, according to their distribution in the groups.

\begin{tabular}{|c|c|c|c|c|}
\hline & \multicolumn{3}{|c|}{ Groups } & \multirow[b]{2}{*}{$p$ value } \\
\hline & $\begin{array}{l}\text { Ondansetron } \\
\qquad(\mathrm{n}=30)\end{array}$ & $\begin{array}{l}\text { P6 acupuncture } \\
\quad(\mathrm{n}=30)\end{array}$ & $\begin{array}{l}\text { P6 acupuncture } \\
\text { plus ondansetron } \\
\qquad(\mathrm{n}=30)\end{array}$ & \\
\hline \multicolumn{5}{|l|}{ Nausea } \\
\hline PACU & $7(23.3)$ & $8(26.7)$ & $4(13.3)$ & 0.519 \\
\hline Surgical ward (0 to 24 hours) & $22(73.3)$ & $10(33.3)^{\mathrm{a}}$ & $5(16.0)^{\mathrm{b}}$ & $<0.001$ \\
\hline \multicolumn{5}{|l|}{ Vomiting } \\
\hline $\mathrm{PACU}$ & $2(6.7)$ & $2(6.7)$ & $4(13.3)$ & 0.724 \\
\hline Surgical ward (0 to 24 hours) & $13(43.3)$ & $8(26.7)$ & $0^{\mathrm{c,d}}$ & $<0.001$ \\
\hline
\end{tabular}

trical stimulation of $\mathrm{P} 6$ acupoint is also suggested to be more practical than manual needling, even though the efficacy on the reduction of PONV may not be different [23]. Another aspect of interest is the period and time of electrical stimulation. A more prolonged stimulation seems to be more effective than a short period or just preoperative stimulation [24]. Thinking of a more feasible procedure and patients' comfort, we decided to do just a 30-minute preoperative electrical stimulation of P6.

The use of opioids during the perioperative period is strongly associated with an increased incidence of postoperative nausea and vomiting. In patients undergoing ambulatory surgery, it was found a dose-dependent incidence of PONV in the post anesthesia care unit with fentanil systemically administered [25]. Intrathecal use o morphine results in increased incidence of PONV [26] and prophylaxis is highly recommended [27].

Acupuncture has become one of the commonest sought therapies among those considered as unconventional, alternative or unorthodox, for different medical conditions [28]. Nonetheless, its theoretical background based on the metaphysical concepts of energy from the traditional Chinese medicine may not be clear and not associated with the basis of the scientific disciplines, such as biochemistry, physiology and pharmacology and, for this reason, disapproved by the scientific community [29]. Despite its metaphysics background, there are several hypotheses concerning its physiological effects for some clinical conditions, including local intramuscular effect, nerve stimulation, autonomic system stimulation and increased secretion of endorphin [29] [30] [31].

Results concerning any kind of stimulation of P6 acupoint for the treatment of postoperative nausea and vomiting after general anesthesia are conflicting, sometimes indicating a reduction in the incidence of postoperative nausea, sometimes in the incidence of postoperative vomiting and sometimes not showing any clear advantage over a pharmacological therapy. After awaking, patients 
submitted to appendectomy under general anesthesia had a wristband positioned around P6 acupoint, and pressure was applied for seven hours after surgery. Control group had a sham wristband with no pressure applied on P6 acupoint. The incidence of nausea was no different between the groups but P6 acupoint pressure reduced the incidence of vomiting [32].

In gynecological patients undergoing laparoscopic surgery, considered a high-risk group of patients for PONV, the combination of electrical stimulation of P6 and the use of dexamethasone reduced the incidence of nausea during 24 hours after surgery when compared to the use of dexamethasone alone. These results were comparable to those obtained with the prophylaxis with the use of tropisetron in combination with dexamethasone, when compared to the use of dexamethasone alone. The incidence of vomiting in the first 24 hours were $18 \%$, $15 \%$ and $24 \%$ for the combination of electrical stimulation of P6 acupoint and dexamethasone, tropisetron plus dexamethasone and dexamethasone alone, respectively, with no significant differences among groups [33].

In women undergoing gynecological or abdominal laparoscopy under sevoflurane-fentanil anesthesia, neuromuscular blockade was monitored by a conventional nerve stimulator over the ulnar nerve, used as control group, or over the median nerve, corresponding to P6 acupoint. The incidence of nausea decreased significantly from $56 \%$ in the control group to $40 \%$ in the P6 group during the first 6 hours postoperatively but emesis was not significantly reduced in this period, from $25 \%$ to $16 \%$. During the 24 -hour analysis, overall incidence of nausea was significantly reduced from $56 \%$ to $40 \%$ by the P6 group but the incidence of emesis was not statistically different, $28 \%$ to $23 \%$, in control and P6 groups, respectively [34].

In children undergoing tonsillectomy/adenoidectomy, blinded P6 acupoint electrical stimulation was compared to sham acupuncture (electrical stimulation of acupuncture needles in different sites other than P6) or control group (no acupuncture). Acupuncture needles were placed while patients were anesthetized, and low-frequency electrical stimulation was applied to these points for 20 minutes in the recovery room. PONV was evaluated for 24 hours. The incidence of nausea was reduced by P6 acupuncture (60\%) but not by sham acupuncture (85\%) compared with controls (93\%). The incidence of vomiting was not significantly different with P6 acupuncture (63\%) or sham acupuncture (88\%) compared with controls (78\%) [35].

Literature also shows conflicting results when prevention of PONV with acupuncture is studied in patients undergoing spinal anesthesia. Parturients receiving epidural morphine for post cesarean section pain relief were allocated to receive the acupressure bands or placebo bands on the P6 acupoint bilaterally before the administration of spinal anesthesia and were observed over a 48-hour period. The incidence of nausea and vomiting was significantly decreased from $43 \%$ and $27 \%$ in the control group to $3 \%$ and $0 \%$ in the acupressure group, respectively [36]. Nonetheless, in elective cesarean section under spinal anesthesia, 
preoperative electrical stimulation of P6 reduced the incidence of nausea and vomiting during the first 6 hours after surgery in comparison to non-treated patients but had equivalent efficacy with $4 \mathrm{mg}$ of ondansetron administered 30 minutes before anesthesia [37]. In another study with patients undergoing cesarean section under spinal anesthesia, transcutaneous preoperative P6 acupoint electrical stimulation was compared with dorsum of the wrist stimulation (sham group). The incidence of postoperative nausea was $23 \%$ and $41 \%$ and the incidence of vomiting was $26 \%$ and $37 \%$ for P6 electrical stimulation and sham groups, respectively, with no statistical difference detected [38].

Even though the majority of the studies on the prevention of PONV with acupuncture use the P6 acupoint, other acupoints have been studied showing a decrease in the incidence of PONV when compared to placebo or sham acupuncture [39] [40].

Our study has some limitations. The patients were not blinded to the treatments and due to ethical issues our study was not placebo-controlled. Nonetheless, the outcome evaluators were unaware of the groups studied.

\section{Conclusion}

We concluded that preoperative electrical stimulation of P6 acupoint in combination with intravenous administration of ondansetron has a higher efficacy than either the administration of ondansetron or P6 acupoint electrical stimulation on the prevention of the occurrence of PONV in patients submitted to bupivacaine-morphine spinal anesthesia. Despite the lack of a complete understanding of the effects and mechanism of action of acupuncture, considering the results of this study, we recommend that acupuncture be an option as an adjunct therapy to ondansetron on the prevention of PONV, a very unpleasant complication related to the surgical/anesthetic intervention.

\section{References}

[1] Apfel, C.C., Laara, E., Koivuranta, M., Greim, C.A. and Roewer, N. (1999) A Simplified Risk Score for Predicting Postoperative Nausea and Vomiting: Conclusions from Cross-Validations between Two Centers. Anesthesiology, 91, 693-700. https://doi.org/10.1097/00000542-199909000-00022

[2] Gan, T.J. (2002) Postoperative Nausea and Vomiting-Can It Be Eliminated? The Journal of the American Medical Association, 287, 1233-1236. https://doi.org/10.1001/jama.287.10.1233

[3] Carlisle, J.B. and Stevenson, C.A. (2006) Drugs for Preventing Postoperative Nausea and Vomiting. Cochrane Database of Systematic Reviews, CD004125. https://doi.org/10.1002/14651858.CD004125.pub2

[4] Kumar, G., Stendall, C., Mistry, R., Gurusamy, K. and Walker, D. (2014) A Comparison of Total Intravenous Anaesthesia Using Propofol with Sevoflurane or Desflurane in Ambulatory Surgery: Systematic Review and Meta-Analysis. Anaesthesia, 69, 1138-1150. https://doi.org/10.1111/anae.12713

[5] Voigt, M., Frohlich, C.W., Waschke, K.F., Lenz, C., Gobel, U. and Kerger, H. (2011) Prophylaxis of Postoperative Nausea and Vomiting in Elective Breast Surgery. 
Journal of Clinical Anesthesia, 23, 461-468.

https://doi.org/10.1016/j.jclinane.2011.01.005

[6] Kim, G.H., Ahn, H.J., Kim, H.S., Bang, S.R., Cho, H.S., Yang, M. and Kim, J.A. (2011) Postoperative Nausea and Vomiting after Endoscopic Thyroidectomy: Total Intravenous vs. Balanced Anesthesia. Korean Journal of Anesthesiology, 60, 416-421. https://doi.org/10.4097/kjae.2011.60.6.416

[7] Sprung, J., Choudhry, F.M. and Hall, B.A. (2003) Extrapyramidal Reactions to Ondansetron: Cross-Reactivity between Ondansetron and Prochlorperazine? Anesthesia \& Analgesia, 96, 1374-1376. https://doi.org/10.1213/01.ANE.0000058845.72102.F2

[8] Tolan, M.M., Fuhrman, T.M., Tsueda, K. and Lippmann, S.B. (1999) Perioperative Extrapyramidal Reactions Associated with Ondansetron. Anesthesiology, 90, 340-341. https://doi.org/10.1097/00000542-199901000-00073

[9] Leslie, K., Myles, P.S., Chan, M.T., Paech, M.J., Peyton, P., Forbes, A., McKenzie, D. and Group, E.T. (2008) Risk Factors for Severe Postoperative Nausea and Vomiting in a Randomized Trial of Nitrous Oxide-Based vs Nitrous Oxide-Free Anaesthesia. British Journal of Anaesthesia, 101, 498-505. https://doi.org/10.1093/bja/aen230

[10] Jokinen, J., Smith, A.F., Roewer, N., Eberhart, L.H. and Kranke, P. (2012) Management of Postoperative Nausea and Vomiting: How to Deal with Refractory PONV. Anesthesiology Clinics, 30, 481-493. https://doi.org/10.1016/j.anclin.2012.07.003

[11] Helmreich, R.J., Shiao, S.Y. and Dune, L.S. (2006) Meta-Analysis of Acustimulation Effects on Nausea and Vomiting in Pregnant Women. Explore, 2, 412-421.

[12] Shin, H.S., Song, Y.A. and Seo, S. (2007) Effect of Nei-Guan Point (P6) Acupressure on Ketonuria Levels, Nausea and Vomiting in Women with Hyperemesis Gravidarum. Journal of Advanced Nursing, 59, 510-519. https://doi.org/10.1111/j.1365-2648.2007.04342.x

[13] Shen, Y., Liu, L., Chiang, J.S., Meng, Z., Garcia, M.K., Chen, Z., Peng, H., Bei, W., Zhao, Q., Spelman, A.R. and Cohen, L. (2015) Randomized, Placebo-Controlled Trial of K1 Acupoint Acustimulation to Prevent Cisplatin-Induced or Oxaliplatin-Induced Nausea. Cancer, 121, 84-92. https://doi.org/10.1002/cncr.28973

[14] Rithirangsriroj, K., Manchana, T. and Akkayagorn, L. (2015) Efficacy of Acupuncture in Prevention of Delayed Chemotherapy Induced Nausea and Vomiting in Gynecologic Cancer Patients. Gynecology Oncology, 136, 82-86.

[15] Liodden, I., Sandvik, L., Valeberg, B.T., Borud, E. and Norheim, A.J. (2015) Acupuncture versus Usual Care for Postoperative Nausea and Vomiting in Children after Tonsillectomy/Adenoidectomy: A Pragmatic, Multicentre, Double-Blinded, Randomised Trial. Acupuncture in Medicine, 33, 196-203.

https://doi.org/10.1136/acupmed-2014-010738

[16] Zarate, E., Mingus, M., White, P.F., Chiu, J.W., Scuderi, P., Loskota, W. and Daneshgari, V. (2001) The Use of Transcutaneous Acupoint Electrical Stimulation for Preventing Nausea and Vomiting after Laparoscopic Surgery. Anesthesia \& Analgesia, 92, 629-635. https://doi.org/10.1213/00000539-200103000-00014

[17] Cheong, K.B., Zhang, J.P., Huang, Y. and Zhang, Z.J. (2013) The Effectiveness of Acupuncture in Prevention and Treatment of Postoperative Nausea and Vomiting-A Systematic Review and Meta-Analysis. PLOS ONE, 8, e82474. https://doi.org/10.1371/journal.pone.0082474

[18] Matthews, A., Dowswell, T., Haas, D.M., Doyle, M. and O’Mathuna, D.P. (2010) Interventions for Nausea and Vomiting in Early Pregnancy. Cochrane Database of Systematic Reviews, CD007575. https://doi.org/10.1002/14651858.CD007575.pub2 
[19] Van den Heuvel, E., Goossens, M., Vanderhaegen, H., Sun, H.X. and Buntinx, F. (2016) Effect of Acustimulation on Nausea and Vomiting and on Hyperemesis in Pregnancy: A Systematic Review of Western and Chinese Literature. BMC Complementary and Alternative Medicine, 16, 13. https://doi.org/10.1186/s12906-016-0985-4

[20] Garcia, M.K., McQuade, J., Haddad, R., Patel, S., Lee, R., Yang, P., Palmer, J.L. and Cohen, L. (2013) Systematic Review of Acupuncture in Cancer Care: A Synthesis of the Evidence. Journal of Clinical Oncology, 31, 952-960.

https://doi.org/10.1200/JCO.2012.43.5818

[21] Lee, A., Chan, S.K. and Fan, L.T. (2015) Stimulation of the Wrist Acupuncture Point PC6 for Preventing Postoperative Nausea and Vomiting. Cochrane Database of Systematic Reviews, CD003281.

https://doi.org/10.1002/14651858.CD003281.pub4

[22] Dundee, J.W., Chestnutt, W.N., Ghaly, R.G. and Lynas, A.G. (1986) Traditional Chinese Acupuncture: A Potentially Useful Antiemetic? British Medical Journal, 293, 583-584. https://doi.org/10.1136/bmj.293.6547.583

[23] Ghaly, R.G., Fitzpatrick, K.T. and Dundee, J.W. (1987) Antiemetic Studies with Traditional Chinese Acupuncture. A Comparison of Manual Needling with Electrical Stimulation and Commonly Used Antiemetics. Anaesthesia, 42, 1108-1110. https://doi.org/10.1111/j.1365-2044.1987.tb05180.x

[24] White, P.F., Hamza, M.A., Recart, A., Coleman, J.E., Macaluso, A.R., Cox, L., Jaffer, O., Song, D. and Rohrich, R. (2005) Optimal Timing of Acustimulation for Antiemetic Prophylaxis as an Adjunct to Ondansetron in Patients Undergoing Plastic Surgery. Anesthesia \& Analgesia, 100, 367-372. https://doi.org/10.1213/01.ANE.0000144425.16116.0A

[25] Apfel, C.C., Philip, B.K., Cakmakkaya, O.S., Shilling, A., Shi, Y.Y., Leslie, J.B., Allard, M., Turan, A., Windle, P., Odom-Forren, J., Hooper, V.D., Radke, O.C., Ruiz, J. and Kovac, A. (2012) Who Is at Risk for Postdischarge Nausea and Vomiting after Ambulatory Surgery? Anesthesiology, 117, 475-486.

https://doi.org/10.1097/ALN.0b013e318267ef31

[26] Kuchalik, J., Granath, B., Ljunggren, A., Magnuson, A., Lundin, A. and Gupta, A. (2013) Postoperative Pain Relief after Total Hip Arthroplasty: A Randomized, Double-Blind Comparison between Intrathecal Morphine and Local Infiltration Analgesia. British Journal of Anaesthesia, 111, 793-799.

https://doi.org/10.1093/bja/aet248

[27] Harnett, M.J., O’Rourke, N., Walsh, M., Carabuena, J.M. and Segal, S. (2007) Transdermal Scopolamine for Prevention of Intrathecal Morphine-Induced Nausea and Vomiting after Cesarean Delivery. Anesthesia and Analgesia, 105, 764-769. https://doi.org/10.1213/01.ane.0000277494.30502.db

[28] Eisenberg, D.M., Kessler, R.C., Foster, C., Norlock, F.E., Calkins, D.R. and Delbanco, T.L. (1993) Unconventional Medicine in the United States. Prevalence, Costs, and Patterns of Use. The New England Journal of Medicine, 328, 246-252. https://doi.org/10.1056/NEJM199301283280406

[29] Cheng, K.J. (2009) Neuroanatomical Basis of Acupuncture Treatment for Some Common Illnesses. Acupuncture in Medicine, 27, 61-64. https://doi.org/10.1136/aim.2009.000455

[30] Kawakita, K., Shinbara, H., Imai, K., Fukuda, F., Yano, T. and Kuriyama, K. (2006) How Do Acupuncture and Moxibustion Act?-Focusing on the Progress in Japanese Acupuncture Research. Journal of Pharmacological Sciences, 100, 443-459. https://doi.org/10.1254/jphs.CRJ06004X 
[31] Tang, Y., Yin, H.Y., Rubini, P. and Illes, P. (2016) Acupuncture-Induced Analgesia: A Neurobiological Basis in Purinergic Signaling. Neuroscientist, 22, 563-578. https://doi.org/10.1177/1073858416654453

[32] Adib-Hajbaghery, M., Etri, M., Hosseainian, M. and Mousavi, M.S. (2013) Pressure to the p6 Acupoint and Post-Appendectomy Pain, Nausea, and Vomiting: A Randomized Clinical Trial. Journal of Caring Sciences, 2, 115-122.

[33] Yang, X.Y., Xiao, J., Chen, Y.H., Wang, Z.T., Wang, H.L., He, D.H. and Zhang, J. (2015) Dexamethasone Alone vs. in Combination with Transcutaneous Electrical Acupoint Stimulation or Tropisetron for Prevention of Postoperative Nausea and Vomiting in Gynaecological Patients Undergoing Laparoscopic Surgery. British Journal of Anaesthesia, 115, 883-889. https://doi.org/10.1093/bja/aev352

[34] Arnberger, M., Stadelmann, K., Alischer, P., Ponert, R., Melber, A. and Greif, R. (2007) Monitoring of Neuromuscular Blockade at the P6 Acupuncture Point Reduces the Incidence of Postoperative Nausea and Vomiting. Anesthesiology, 107, 903-908. https://doi.org/10.1097/01.anes.0000290617.98058.d9

[35] Rusy, L.M., Hoffman, G.M. and Weisman, S.J. (2002) Electroacupuncture Prophylaxis of Postoperative Nausea and Vomiting Following Pediatric Tonsillectomy with or without Adenoidectomy. Anesthesiology, 96, 300-305.

https://doi.org/10.1097/00000542-200202000-00013

[36] Ho, C.M., Hseu, S.S., Tsai, S.K. and Lee, T.Y. (1996) Effect of P-6 Acupressure on Prevention of Nausea and Vomiting after Epidural Morphine for Post-Cesarean Section Pain Relief. Acta Anaesthesiologica Scandinavica, 40, 372-375. https://doi.org/10.1111/j.1399-6576.1996.tb04448.x

[37] El-Deeb, A.M. and Ahmady, M.S. (2011) Effect of Acupuncture on Nausea and/or Vomiting during and after Cesarean Section in Comparison with Ondansetron. Journal of Anesthesia, 25, 698-703. https://doi.org/10.1007/s00540-011-1198-0

[38] Habib, A.S., Itchon-Ramos, N., Phillips-Bute, B.G., Gan, T.J. and Duke Women's Anesthesia Research, G. (2006) Transcutaneous Acupoint Electrical Stimulation with the Relief Band for the Prevention of Nausea and Vomiting during and after Cesarean Delivery under Spinal Anesthesia. Anesthesia \& Analgesia, 102, 581-584. https://doi.org/10.1213/01.ane.0000189217.19600.5c

[39] Jiang, Y.H., Jiang, W., Jiang, L.M., Lin, G.X., Yang, H., Tan, Y. and Xiong, W.W. (2010) Clinical Efficacy of Acupuncture on the Morphine-Related Side Effects in Patients Undergoing Spinal-Epidural Anesthesia and Analgesia. Chinese Journal of Integrative Medicine, 16, 71-74. https://doi.org/10.1007/s11655-010-0070-7

[40] Koo, M.S., Kim, K.S., Lee, H.J., Jeong, J.S. and Lee, J.W. (2013) Antiemetic Efficacy of Capsicum Plaster on Acupuncture Points in Patients Undergoing Thyroid Operation. Korean Journal of Anesthesiology, 65, 539-543.

https://doi.org/10.4097/kjae.2013.65.6.539 
Submit or recommend next manuscript to SCIRP and we will provide best service for you:

Accepting pre-submission inquiries through Email, Facebook, LinkedIn, Twitter, etc. A wide selection of journals (inclusive of 9 subjects, more than 200 journals)

Providing 24-hour high-quality service

User-friendly online submission system

Fair and swift peer-review system

Efficient typesetting and proofreading procedure

Display of the result of downloads and visits, as well as the number of cited articles Maximum dissemination of your research work

Submit your manuscript at: http://papersubmission.scirp.org/

Or contact ojanes@scirp.org 